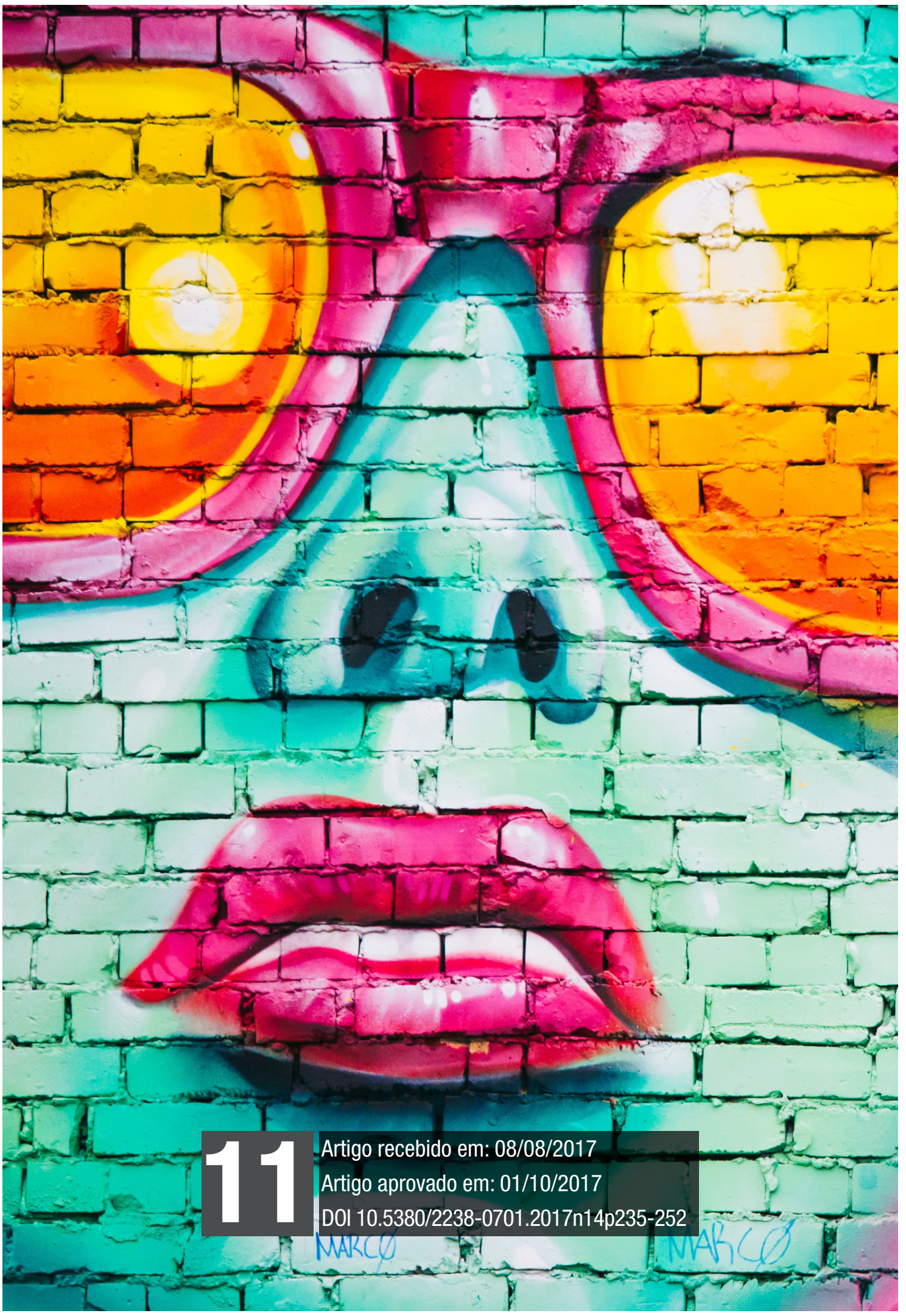


Feminismo. Marca. Consumo. Cerveja. 


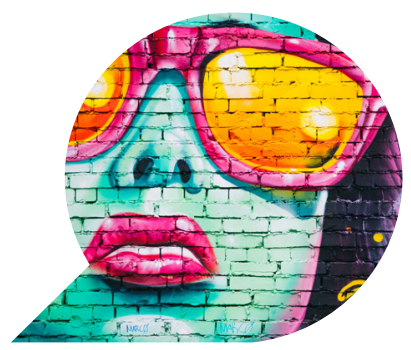

\section{A (des)construção do papel da mulher em campanhas publicitárias de cerveja: análise da campanha Reposter da Skol}

The (des)construction of the role of women in beer advertising campaigns: Skol's Reposter campaign analysis

La (des)construcción del papel de la mujer en campañas publicitarias de cerveza: análisis de la campaña Reposter de Skol

\begin{tabular}{c}
\hline CRISTIANO MAX PINHEIRO $^{*}$ \\
\hline DÉBORA WISSMANN \\
\hline CAMI*A MELO FERRARELI \\
\hline
\end{tabular}

Resumo: A mulher é vista como objeto de consumo em muitas campanhas publicitárias de cerveja. Esse fator influencia na forma como a mulher é vista pela sociedade e a forma como ela é tratada. A Skol, em sua campanha Reposter, mudou o seu discurso quanto ao papel da mulher nas propagandas. Por meio da análise dessa campanha, com conceitos sobre marca e identidade de Semprini (2006), Aaker (2001), Tavares (2003), entre outros; uma visão da

\footnotetext{
* Doutor em Comunicação pela PUCRS. Professor do mestrado em Indústria Criativa na Universidade Feevale. E-mail: maxrs@feevale.br

** Estudante de graduação do 8º semestre de Publicidade e Propaganda na Universidade Feevale.

*** Estudante de graduação do $6^{\circ}$ semestre de Jornalismo na Universidade Feevale.
} 
mulher nas campanhas publicitárias, com Cruz (2008) e Abdala (2008), e uma contextualização do feminismo no Brasil baseada em Vidal (2005), Cestari (2008), Castells (2002), foi possível verificar que a Skol conseguiu reconhecer os erros do passado e manter uma identidade de marca coerente, e o quanto esta mudança é importante para a luta pela igualdade de gêneros.

Palavras-chave: Feminismo; Marca; Objeto de consumo; Skol.

Abstract: Women have been seen as objects of consumption in many beer-advertising campaigns. This factor has influenced in which way a woman is viewed by society and the way she is treated. Skol, in its Reposter campaign, changed its speech on the role of women in advertising. Through the analysis of this campaign, with concepts about brand and identity of Semprini (2006), Aaker (2001), Tavares (2003), among others; a view of women in advertising campaigns, with Cruz (2008), Abdala (2008) and a contextualization of feminism in Brazil based on Vidal (2005), Cestari (2008), Castells (2002), it was possible to verify that Skol recognized the mistakes of the past and now maintain a consistent brand identity. This is an important step and shows the importance of this change is in the discussion for gender equality.

Key words: Feminism; Brand; Object of consumption; Skol.

Resumen: La mujer es vista como objeto de consumo en muchas campañas publicitarias de cerveza. Este factor influye en la forma con que la mujer es vista por la sociedad y la forma en que ella es tratada. Skol, en su campaña Reposter, cambió su discurso en cuanto al papel de la mujer en las propagandas. A través del análisis de esta campaña, con conceptos sobre marca e identidad de Semprini (2006), Aaker (2001), Tavares (2003), entre otros; una visión de la mujer en las campañas publicitarias, con Cruz (2008) y Abdala (2008), y una contextualización del feminismo en Brasil basada en Vidal (2005), Cestari (2008), Castells (2002), fue posible verificar que la Skol logró reconocer los errores del pasado y mantener una identidad de marca coherente y cuanto este cambio es importante para la lucha por la igualdad de géneros.

Palabras clave: Feminismo; Marca; Objeto de consumo; Skol. 


\section{Introdução}

A publicidade tem o poder de persuasão sobre as pessoas. "Persuadir é construir no terreno da ação: quando persuadimos alguém, esse alguém realiza algo que desejamos que ele realize" (RIBEIRO, 2005, p. 410). Sabendo disso, muitas empresas estão cada vez mais preocupadas e engajadas com fatos que estão ocorrendo em nossa sociedade, principalmente em relação ao papel da mulher em diversas campanhas. De fato, é muito importante que tais assuntos sejam explorados pela publicidade por conta desse poder de persuasão. Mas o que muitas empresas têm dificuldade em perceber é que para explorar alguma questão social, esta precisa condizer com a sua realidade, pois caso contrário corre o risco de diminuir sua reputação perante os consumidores.

Toda marca possui valores que são passados para os consumidores. Os consumidores, mesmo não utilizando o produto, podem gostar da marca somente por causa dos valores que a marca transmite. As identificações são feitas pelo consumidor por conta do discurso da marca. Por isso, algumas marcas perceberam que a sociedade mudou e que, com isso, elas também deveriam mudar o seu discurso. De fato, é muito importante que assuntos antes silenciados sejam explorados pela publicidade. Mas o que muitas marcas deixam de lado é que para explorar alguma questão social, esta precisa condizer com a sua realidade, pois caso isso não ocorra, corre o risco de diminuir a sua reputação perante os consumidores, pois segundo Tavares (2003, p. 121), "uma marca deve ser concebida, construída e posicionada, observando-se inicialmente o mercado - e as mentes com as quais se irá trabalhar -, com o objetivo de se definir um foco diferenciado e estreito para ter chances de ser percebido com singularidade".

Vieira (2002) traz o conceito que a marca nasce com um ideal, e que nenhum plano se torna eficiente se a marca construir uma campanha baseada em conceitos artificiais. Além disso, o autor comenta que "a verdade da marca é a verdade dos sentimentos das pessoas que lidam com ela. E a verdade, para esse fim, é o que faz sentido para o coração" (VIEIRA, 2002 p. 16).

\section{O feminismo e a "mulher-objeto"}

A questão de gênero é muitas vezes abordada por autores como a distinção entre o feminino e o masculino. O que distingue o macho e a 
fêmea é o sexo, que diz respeito à função biológica do ser vivo. O gênero, por sua vez, engloba o conceito de funções na sociedade. Sendo assim, o gênero varia de cultura para cultura (LOURO, 1996).

Para Simone de Beauvoir (1949), ser homem ou mulher não consiste em apenas possuir as características físicas ou biológicas de sexo e gênero, mas sim, na construção social que é imposta ao ser humano. A mulher, então, cresce pensando que é frágil e constrói todo o estereótipo de feminilidade que é conhecido. A partir das ideias de Beauvoir (1949), quando foi entendido o que é ser mulher, surgiram grandes movimentos que tentam desmistificar a mulher como um ser frágil. O Feminismo se apoia nessas ideias de construção social para basear sua luta por igualdade.

De acordo com Vidal (2005) o feminismo tem como finalidade pleitear direitos para a mulher, na condição de ser humano e, com isso, fazer com que exista igualdade aos homens. O feminismo é um movimento social que surgiu através dos ideais da Revolução Francesa: fraternidade, igualdade e liberdade. Ao surgir no Brasil, o movimento feminista foi rotulado como um ato de rebeldia que deveria ser combatido. Cestari (2008) diz que as mulheres da classe média do Rio de Janeiro e de São Paulo, que tinham interesses políticos similares, formaram os primeiros grupos feministas a partir de 1972 . Hall (2001, p. 44) nos traz que "o feminismo faz parte daquele grupo de 'novos movimentos sociais', que emergiram durante os anos sessenta”. No início do movimento, as mulheres buscavam garantir o direito de trabalhar e a igualdade de salários, participação na política, liberdade sexual, direitos estes que os homens sempre possuíram. O movimento feminista começa no Brasil na década de 1970, mas não tem efeitos tão rápido.

Por muito tempo, a mulher foi tida como objeto, ou "mulher-objeto" (MORIN, 2007). Segundo Heldman (2012), a objetificação sexual é a representação de uma pessoa como um objeto sexual. O que acontece com as mulheres, por terem sido sempre submissas aos homens, é um constante processo de objetificação que reflete em todas as sociedades. Para Abdala (2008, p. 113), a "bulimia, anorexia, consumo patológico, ansiedade, vergonha, medo, insegurança, entre tantos outros problemas que atingem as mulheres, podem ter uma parcela de sua origem nos mecanismos de vaidade potencializados pelo mercado".

Em uma sociedade patriarcal, como é a brasileira, as relações interpessoais e a própria personalidade são marcadas pela dominação e pela violência (CASTELLS, 2002). Essa teoria é percebida na prática: segundo o Mapa da Violência 2015 - Homicídio de Mulheres, da Flasco 
Brasil, 106 mil mulheres foram assassinadas entre 1980 e 2013. Segundo a OMS, em um ranking de 83 países, o Brasil ocupa o $5^{\circ}$ lugar na posição internacional de violência contra a mulher.

A violência se dá por diversos meios. De acordo com Pamplona (2001), o assédio se caracteriza como qualquer conduta de natureza sexual que não seja desejada e que, embora o assediado tente negar, o assediador não para, tirando a liberdade sexual do indivíduo. O assédio é feito por alguém superior a vítima.

As imagens mostram, os comportamentos provam, as expectativas confirmam: a beleza não tem o mesmo valor no masculino e no feminino. Os cartazes publicitários e as capas de revista, a linguagem e as canções, a moda e as manequins, o olhar dos homens e o desejo das mulheres, tudo nos lembra com insistência a condição privilegiada da beleza da mulher, a identificação desta com o 'belo sexo' (LIPOVETSKY, 2000, p. 101).

As campanhas publicitárias, ao trazerem a mulher como um objeto de consumo que serve aos homens, acabam contribuindo para tornar normais e cotidianas as situações de assédio e violência que temos na sociedade. Para Morin (2007, p. 120), "se operou uma espantosa conjunção entre o erotismo feminino e o próprio movimento do capitalismo moderno, que procura estimular o consumo".

\section{Identidade da marca e a mulher nas campanhas de cerveja}

A marca é tão antiga quanto o comércio e, acompanhando o progresso da civilização industrial, hoje é tema de debate, pois o seu desenvolvimento a levou "para além de seu perímetro natural de ação, aquele de mercado e de consumo de bens e serviços" (SEMPRINI, 2006, p. 261). Para Tavares (2003, p. 55), as marcas e o papel que as mesmas desempenham "estão diretamente ligados à história e à evolução da sociedade de consumo".

$\mathrm{O}$ aspecto perceptual da marca existe na mente do consumidor. O que nos permite ter acesso a mente do consumidor é a publicidade, e a partir da percepção de imagens, símbolos e sensações, o consumidor percebe a marca (RANDAZZO, 1997). Através da publicidade, pode-se "criar mundos e personagens míticos que [...] ficam associados a nosso produto e que finalmente passam a definir nossa marca" (RANDAZZO, 1997, p. 27).

Randazzo (1997, p. 24) destaca que: 
A marca é mais do que um produto; é ao mesmo tempo uma entidade física e perceptual. [...] O aspecto físico de uma marca (seu produto e embalagem) pode ser encontrado esperando por nós na prateleira do supermercado (ou onde for). É geralmente estático e finito. Entretanto, o aspecto perceptual de uma marca existe no espaço psicológico - na mente do consumidor. É dinâmico e maleável.

Quando falamos de marcas, falamos de sua identidade, que são atributos que as diferencia das demais. A identidade da marca, segundo Batey (2010, p. 31), é "a percepção do consumidor e sua interpretação de um agrupamento de atributos, benefícios e valores associados a ela”. Aaker (2000, p. 53) conceitua a identidade de marca como

um conjunto de associações de marca que o estrategista deseja criar ou manter. Essas associações implicam uma promessa feita aos clientes pelos membros da organização. Como se utiliza a identidade de marca para impulsionar todos os esforços de construção de marcas, é necessário haver profundidade e riqueza; não é um bordão de propaganda nem sequer uma afirmação de posicionamento.

Para Tavares (1998), a identidade de marca é o apoio para orientar a empresa para satisfazer seus consumidores. Apesar das marcas criarem suas próprias identidades, são as pessoas que criam o seu significado. Tavares (1998, p. 17) ainda aborda que "o produto é o que a empresa fabrica, o que o consumidor compra é a marca. Os produtos não podem falar por si: a marca é que dá o significado e fala por eles". Randazzo (1997, p. 27-28) complementa que "uma marca pode funcionar como portadora de projeções na qual o anunciante projeta os valores e as sensibilidades do consumidor, ou como um distintivo, um meio de expressar e reforçar nossas identidades pessoais e culturais".

Para influenciar os consumidores, a marca precisa ter um posicionamento no mercado. $\mathrm{O}$ conceito de posicionamento é revolucionário para a gestão de marcas e foi criado em 1981 por Ries e Trout, que "definiram o posicionamento como a plataforma sobre a qual as empresas constroem suas marcas, criam estratégias de planejamento e ampliam o relacionamento com os clientes" (WHEELER, 2012, p. 24).

Aaker (2000, p. 37), diz que "o posicionamento da marca pode ajudar a priorizar e focalizar a identidade da marca determinando-se os objetivos de comunicação", possibilitando desta forma que a marca crie 
um discurso coeso. Tavares (1998), nos traz que o posicionamento é relacionado em vincular características da marca com os desejos, expectativas e necessidades do público-alvo. O posicionamento da marca é fundamental, tanto no marketing, quando na gestão de marcas, quanto na publicidade (WHEELER, 2012). Para alcançar bons resultados com o posicionamento da marca é preciso entrar na mente do consumidor e saber o que ele pensa, sente e fala. "O sucesso da marca depende de como ela se comunica com seu público" (TAVARES, 2003, p. 204).

A gestão de marcas, ou branding, para Wheeler (2012, p. 16) “é um processo disciplinado para desenvolver a conscientização e ampliar a fidelidade do cliente, exigindo determinação superior e disposição para investir no futuro". Tavares (2003) nos diz que a marca tem o poder de influenciar o consumidor em seu comportamento de compra, e isto só é possível com um bom programa de branding. "Ele cria na mente do cliente em potencial a percepção de que não há outro produto no mercado como o seu" (TAVARES, 2003, p. 83).

Contribuindo para a discussão, Wheeler (2012, p. 16) traz que

A ideia da gestão de marcas é aproveitar todas as oportunidades para expressar por que as pessoas deveriam escolher uma marca e não outra. O desejo de liderar, de superar a concorrência e de dar aos colaboradores as melhores ferramentas para se comunicarem com os clientes é o motivo pelo qual as empresas utilizam a gestão de marcas.

A marca é percebida pelo público através da expressão gráfica, da expressão filosófica e da experiência, ou seja, ela tem uma imagem ou algo que a represente, uma filosofia, algo para dizer e algo para ser trocado. Tudo isso nos leva para a origem da marca e para seus propósitos (VIEIRA, 2002). Por conta disso, "a imagem, o discurso e a ação devem fazer sentido entre si, como membros de uma mesma família ética" (VIEIRA, 2002, p. 119). Para Semprini (2006, p. 158), um bom discurso deve "identificar uma proposição de tipo semiótica e sociocultural que seja pertinente, original e atraente para um determinado público".

Estes discursos podem se organizar em narrativas explícitas fortemente estruturadas e organizadas, como no caso da comunicação comercial e na publicidade, mas elas podem, igualmente, ser veiculadas por um grande número de outras manifestações de marca, que funcionam então como tantos outros atos discursivos, mesmo não seguindo o mesmo caminho da comunicação publicitária tradicional. (SEMPRINI, 2006, p. 106) 
Quando o discurso aparenta ser de verdade, falamos que ele produz um efeito verdadeiro. Então, os mecanismos utilizados no discurso "são usados para construir tal sentido porque, assumido como tal, leva à aceitação do valor proposto (PERUZZOLO, 2002, p. 219). Não devemos nos espantar com a evolução das marcas e de seus discursos, pois existe uma "ampliação da lógica de marca ao espaço social além da esfera comercial” (SEMPRINI, 2006, p. 262).

Em um contexto social, dominada pelo imaterial e regulamentado por uma economia simbólica, é aos discursos sociais que é confinada, em uma medida até então nunca vista, a missão crucial de injetar, fazer circular e fazer absorver a matéria-prima, o componente fundamental do próprio espaço social, a saber, o sentido (SEMPRINI, 2006, p. 262).

Acontece que, quando a marca se utiliza de conceitos que não fazem parte da sua essência, para parecer mais amigável para o público, ela está enganando o seu público e as pessoas para quem os conceitos realmente importam, pois eles reconhecerão a manobra feita pela marca e ela acabará sendo rejeitada. O discurso da marca necessita seguir a lógica de uma narrativa, e todos os "pontos de contato da marca" com as pessoas precisam contar a mesma história, caso contrário, ela perderá sua credibilidade. Apesar de serem impactantes, ações isoladas não são uma estratégia de comunicação sólida (NUNES; CASAGRANDE; MONTEIRO, 2012).

A preocupação das marcas com a sua identidade e com o que transmite ao consumidor deve-se ao fato de que o padrão de consumo está mudando, visto que os consumidores estão menos preocupados em comprar bens para suprir suas necessidades físicas, mas sim em comprar bens que possam ser usados para expressar a sua identidade (BATEY, 2010). Para Randazzo (1997, p. 42), a identidade da marca precisa "representar os seus consumidores-alvos - seus valores, estilos de vida e sensibilidade - ou aquilo que eles gostariam que fossem".

As marcas têm funcionalidades, mas de nada adiantaria se elas não existissem enquanto símbolos, e que pudessem - e o fazem bem - transmitir a diferença e a singularidade para que os indivíduos na sociedade de consumo encontrassem os seus pares para trocas simbólicas, econômicas, sociais, e afirmar a sua identidade enquanto indivíduos - e não só como consumidores - dentro de um coletivo (TAVARES, 2003, p. 87) 
Semprini (2006 p. 69) diz que "o universo do consumo, e principalmente as marcas que o habitam, representa um papel importante na produção de mundos possíveis e que os indivíduos podem, eventualmente, decidir se apropriar destes mundos". Desta forma, Tavares (2003, p. 118) diz que "as marcas conquistam o mercado como entidades físicas e perceptuais, funcionando como resposta psíquica aos desejos e às fantasias de um inconsciente coletivo". Sendo assim, as marcas são influenciadoras da sociedade com os ideais que ela defende e valoriza.

Não devemos nos espantar com esta evolução das marcas e de seus discursos, pois existe uma "ampliação da lógica de marca ao espaço social além da esfera comercial” (SEMPRINI, 2006, p. 262).

Em um contexto social, dominada pelo imaterial e regulamentado por uma economia simbólica, é aos discursos sociais que é confinada, em uma medida até então nunca vista, a missão crucial de injetar, fazer circular e fazer absorver a matéria-prima, o componente fundamental do próprio espaço social, a saber, o sentido.

A mulher que é representada em campanhas publicitárias de cerveja faz jus ao imaginário do brasileiro, apresentando mulheres com corpos esculturais, aparecendo em praias paradisíacas ou em bares cheios de homens esperando para serem servidos por ela. O papel da mulher em muitas campanhas de cerveja é o de objeto de consumo, uma vez que ela representa as características do produto. Nessas campanhas, a mulher não expressa a sua opinião, apenas aparece utilizando roupas sensuais e servindo a cerveja para homens.

Os publicitários criam a propaganda para atingir o senso comum, desse modo, existe um significado do discurso dominante socialmente atribuído à mulher. A cerveja por ela mesma não cria no imaginário social um poder de venda, é necessário ela está ( $\mathrm{sic}$ ) associada a outros valores (atribuídos nesse caso à mulher) para se tornar um objeto de desejo e consumo. Aparecendo ao lado de objetos de consumo, os corpos femininos prometem um paraíso erótico, em suma, são, para nós, os representantes genéricos do que é desejável. (CRUZ, 2008, online).

Com o uso desta imagem pejorativa das mulheres e com a imagem errônea de que a mulher "está presente nas propagandas para ser "consumida" assim como a cerveja" (CRUZ, 2008, online), a mulher aparece 
nas propagandas não como sujeito que expressa uma opinião ou que consome o produto, mas como um objeto, sem vontades e sem vida própria. Quanto a descaracterização da mulher como sujeito, Cruz (2008, online) explica que "é necessário um discurso político eficaz sobre os usos do corpo feminino pela mídia, pois, ao fragmentar a mulher, dando evidência somente a algumas partes do seu corpo, ela não se constitui enquanto sujeito".

É no fluxo da cultura de massa que se desfecha o erotismo: não só os filmes, os comics, as revistas, os espetáculos estão cada vez mais apimentados com imagens eróticas, mas quotidianamente pernas levantadas, peitos estofados, cabeleiras escorridas, lábios entreabertos nos convidam a consumir cigarros, dentifrícios, sabões, bebidas gasosas, toda uma gama de mercadorias cuja finalidade não é, propriamente falando, erótica. (MORIN, 2007, p. 119).

Com as marcas fazendo uso de padrões de beleza quase inatingíveis, muitas mulheres não se sentem mais representadas em campanhas publicitárias. Abdala (2008, p. 109) nos traz que "a mídia, o mundo da moda, a cultura e as empresas que trabalham com esse segmento, projetam imagens de uma beleza ideal a ser mimetizada”. Para Morin (2007, p. 122), "a mulher-objeto, objeto de divertimento, de prazer e de luxo seria, de algum modo, a vítima do cinismo desfrutador do homem”.

A injeção de erotismo na representação de uma mercadoria não erótica (as publicidades que juntam uma atraente imagem feminina a uma geladeira, uma máquina de lavar ou uma soda) tem por função não apenas (ou tanto) provocar diretamente o consumo masculino, mas de estetizar, aos olhos das mulheres, a mercadoria de que elas se apropriarão; ela põe em jogo junto ao eventual cliente a magia da identificação sedutora; a mercadoria faz o papel de mulher desejável, para ser desejada pelas mulheres, apelando para seu desejo em serem desejadas pelos homens. (MORIN, 2007, p. 121).

A medida que as campanhas publicitárias trazem papéis diferentes para o homem e para a mulher, estas contribuem para a desigualdade de gênero.

\section{Análise - campanha Reposter}

A campanha Reposter da Skol, com o slogan "Redondo é sair do seu 
passado", foi lançada no Facebook da marca no dia 08 de Março de 2017, como uma homenagem ao Dia Internacional da Mulher. Com o conceito de que o mundo mudou e evoluiu, a Skol produziu um vídeo, com duração de pouco mais de um minuto, em que oito ilustradoras fazem uma releitura de pôsteres antigos da marca, que mostram a mulher como objeto e hipersexualizadas. As ilustradoras convidadas foram: Camila do Rosário, Carol Rosseti, Elisa Arruda, Eva Uviedo, Evelyn Queiroz - a Negahamburguer, Manuela Eichner, Sirlaney Nogueira e Tainá Criola.

Figura 1 - Postagem da Campanha, 2017

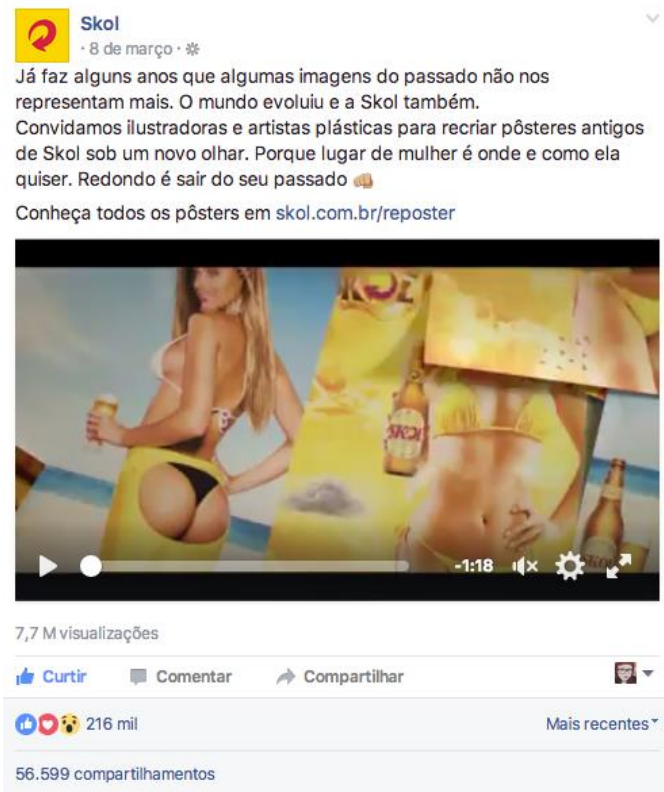

Fonte: Facebook Skol

O vídeo mostra as artistas expressando suas opiniões sobre a marca estar mudando a sua forma de comunicação, principalmente a nova forma que a Skol está enxergando as mulheres. Elas comentam sobre a importância da desconstrução de preconceitos e estereótipos e também do diálogo que a campanha propõe, sendo que uma delas declara que ela quer representar a mulher bebendo a cerveja, e não servindo, o que nos remete ao que vimos com Cruz (2008), de que a mulher atualmente está retratada nas propagandas como submissa ao homem. 
Figura 2 - Pôster recriado pela ilustradora Evelyn Queiroz (direita), 2017

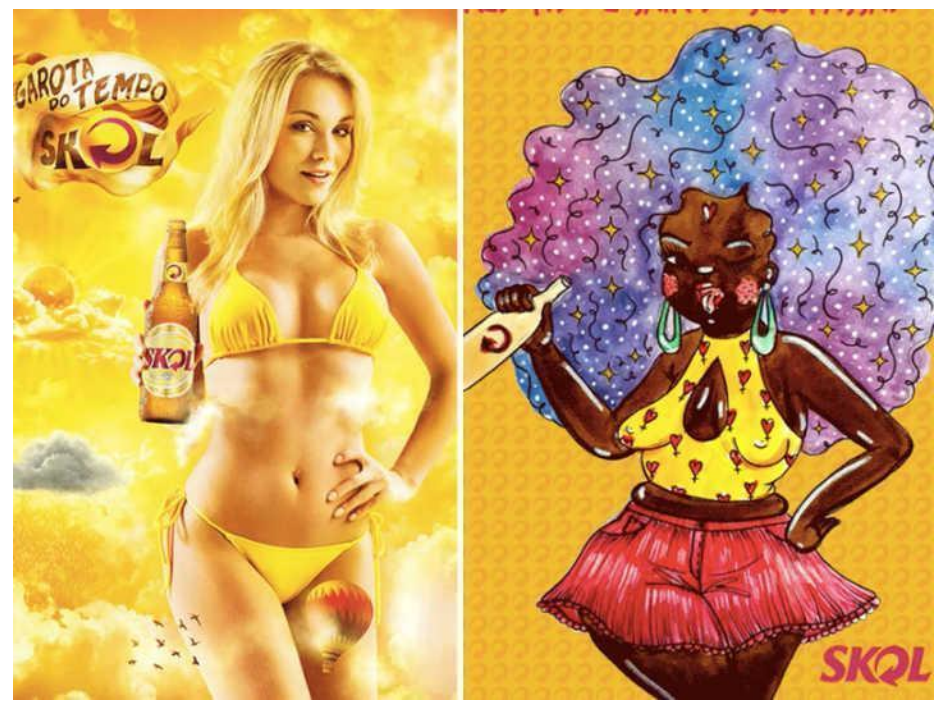

Fonte: Catraca Livre

O resultado da campanha foi a elaboração de pôsteres com estilos diferentes, produzidos por cada uma das ilustradoras e com mensagens de empoderamento feminino. A mensagem transmitida por cada imagem é da mulher que não é objeto de consumo e nem objeto sexual, mas sim consumidora do produto e com opinião formada, ou seja, caracterizada como sujeito.

Figura 3 - Pôsteres da ilustradora Camila do Rosário, 2017, Publicidade e Cerveja
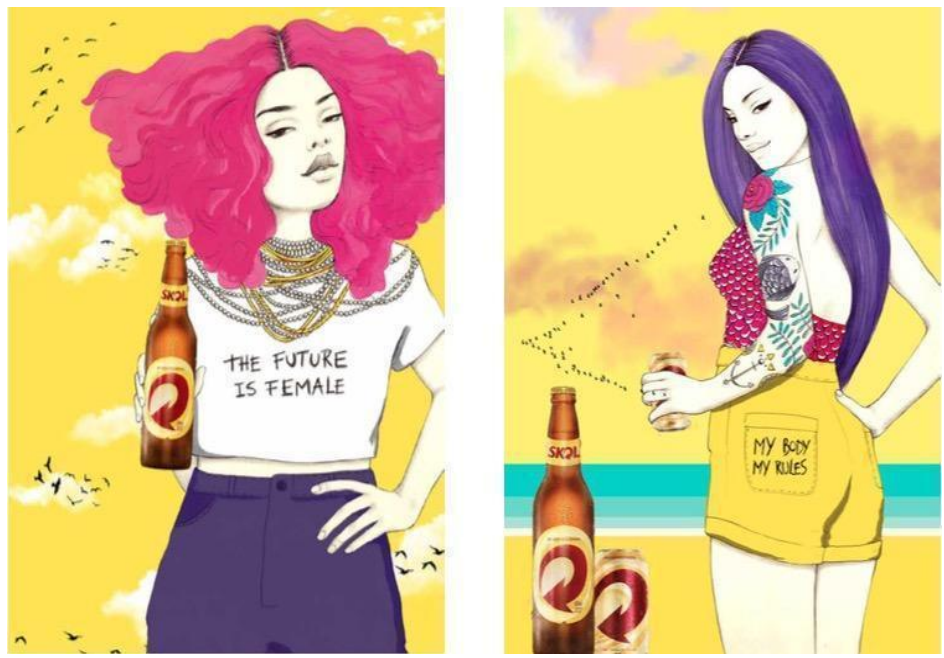
Segundo Tavares (2003), é preciso que a marca tenha comprometimento total com o seu posicionamento. Como mostra a diretora de marketing da Skol, Maria Fernanda de Albuquerque, esse novo posicionamento é a identidade da marca e ela é consequência de uma evolução da Skol:

Toda vez que nos deparamos com peças antigas de SKOL, que mostram posicionamentos distantes do que temos hoje, surge uma vontade de redesenhá-las e reescrevê-las. Então, percebemos que é possível fazer isso e o primeiro passo foi assumir o passado para mostrar a nossa evolução. Para legitimar ainda mais este momento, fizemos questão de dar espaço para mulheres dizerem como gostariam de ser representadas, fazendo essa releitura de pôsteres antigos. Queremos cada vez mais dar voz a quem defende o respeito. Amplificando e aprofundando ações que conversem com o posicionamento da marca. Não é apagar a história. Ela aconteceu, mas ficou no passado. E redondo é deixar para trás o que não te representa mais. (F/NAZCA, 2017).

No final do vídeo, existe a mensagem para que o consumidor avise pelo hotsite caso encontre pôsteres antigos da marca e o local do encontro, para que ele seja substituído. Neste mesmo hotsite, existem mais informações sobre os pôsteres criados e também sobre as ilustradoras. Além disso, é possível enviar seu próprio pôster, que fica disponível neste mesmo hotsite, desde que mostre as mulheres sob uma nova visão e que contenha mensagens positivas e respeitosas (SKOL, 2017).

\section{Considerações finais}

A nova postura e um novo posicionamento das marcas de cerveja em relação ao papel da mulher em suas campanhas é importante para a igualdade de gêneros e a conquista de espaço, tanto no mercado de trabalho quanto ao respeito em outros locais. É uma luta do feminismo buscar a qualidade de ser humano e pela igualdade, mas cabe às marcas mostrarem o apoio a essa causa. Com a Skol mostrando que aprendeu e evoluiu com as campanhas que fez no passado e que precisa reconhecer que aquilo tudo não a representa mais, mostra um grande passo para que a busca pela igualdade continue.

Inserida num sistema capitalista, a campanha Reposter tem como objetivo primário aumentar as vendas de cervejas para a Skol. Entretanto com a influência cada vez maior das marcas na sociedade, é muito importante o levantamento de questões sociais, como essas que o feminismo traz, e desconstruir os estereótipos que foram criados ao longo dos anos. Imagens negativas da mulher nas campanhas, servindo ho- 
mens e sendo consideradas objetos de consumo, somente incitam cada vez mais a violência, a dominação e o abuso de poder sobre ela.

Assim como a Skol mostra na campanha, o mundo evoluiu e é preciso evoluirmos também. Apesar de Tavares (2003 p. 115) dizer que "mudar o que está na cabeça das pessoas é uma tarefa muito difícil", não é impossível. Wheeler (2012, p. 78), citando Schopenhauer, diz que "toda verdade passa por três estágios. No primeiro, ela é ridicularizada. No segundo, é rejeitada com violência. No terceiro, é aceita como óbvia." Isso tudo nos mostra que é preciso mudar e insistir nessa mudança.

\section{REFERÊNCIAS}

AAKER, David A. Como construir marcas líderes. Porto Alegre: Bookman, 2000.

ABDALA, Paulo Ricardo Zilio. Vaidade e consumo: Como a vaidade física influencia o comportamento do consumidor. Porto Alegre: UFRGS, 2008

BATEY, Mark. O significado da marca: como as marcas ganham a vida na mente dos consumidores. Rio de Janeiro: Best Business, 2010.

BEAUVOIR, Simone. Le Deuxième Sexe. Paris: Éditions Gallimard, 1949.

CASTELLS, Manuel. O poder da identidade. Tradução: Klauss Brandini Gerhardt. 3. ed. São Paulo: Paz e Terra, 2002.

CATRACA LIVRE. Skol convida ilustradoras para recriarem pôsteres machistas. Disponível em: $<$ https://catracalivre.com.br/geral/cidadania/indicacao/skol-convidailustradoras-para-recriarem-posteres-machistas/> Acesso em 17 de abril de 2017.

CESTARI, Mariana Jafet. O Movimento Feminista e o Movimento de Mulheres na América latina na década de 1970: Brasil e Argentina. Juiz de Fora, MG: UFJF; ENFF, 2008.

CRUZ, Sabrina Uzêda. A representação da mulher na mídia: Um olhar feminista sobre as propagandas de cerveja. Revista Travessias. 04 ed. ISSN 1982-5935. Educação, Cultura, Linguagem e Arte. 2008. Disponível em <http://www.cult.ufba. br/ enecult2008/14477.pdf> Acesso em 17 abril de 2017.

F/NAZCA. Redondo é sair do seu passado: Skol legitima novo posicionamento e faz releitura de peças publicitárias antigas da marca. Disponível em: $<$ http://www. fnazca.com.br/index.php/2017/ 03/09/reposter/ > Acesso em: 17 abr. 2017.

FACEBOOK. Skol. Disponível em: <https://www.facebook.com/skol/> Acesso em: 18 abr. 2017. 
HALL, Stuart. A identidade cultural na pós-modernidade. 5. ed. Rio de Janeiro, RJ: DP\&amp;A, 2001.

HELDMAN, Caroline. Sexual Objectification. Part 1: What is it? 2012. Disponível em: <http://carolineheldman.me/2012/07/02/sexual-objectification-part-1-what-isit/>. Acesso em: 19 abr. 2017.

HELDMAN, Caroline. Sexual Objectification. Part 2: The harm. 2012. Disponível em: <http://carolineheldman.me/2012/07/06/sexual-objectification-part-2-theharm/>. Acesso em: 19 abr. 2017.

LIPOVETSKY, Gilles. A terceira Mulher: permanência e revolução do feminino. São Paulo: Companhia das Letras, 2000.

MORIN, Edgar. Cultura de massa no século XX: neurose. Rio de Janeiro: Forense Universitária, 2007.

NUNES, Daniela Lompa; CASAGRANDE, Miguel; MONTEIRO, Roger.

Desconstruindo marcas: um mergulho bem (ou mal) humorado no universo do branding. Porto Alegre: Entrementes Editorial, 2012.

PAMPLONA Filho, Rodolfo. O assédio sexual na relação de emprego. São Paulo: Imprenta, 2001.

PERUZZOLO, Adair Caetano. A estratégia dos signos: quando aprender é fazer. Santa Maria: FACOS/UFSM, 2002.

PUBLICIDADE E CERVEJA. Redondo é sair do seu passado: Skol legitima novo posicionamento e faz releitura de peças publicitárias antigas da marca. Disponível em: <https://publicidadeecerveja.com/2017/03/09/redondo-e-sair-do-seu-passadoskol-legitima-novo-posicionamento-e-faz-releitura-de-pecas-publicitarias-antigasda-marca/> Acesso em: 17 abr. 2017.

RANDAZZO, Sal. A criação de mitos na publicidade: como os publicitários usam o poder do mito e do simbolismo para criar marcas de sucesso. Rio de Janeiro: Rocco, 1997.

RIBEIRO, Manoel Pinto. Gramática aplicada da língua portuguesa. 15. ed. Rio de Janeiro: Metáfora, 2005.

SEMPRINI, Andrea. A marca pós-moderna: poder e fragilidade da marca na sociedade contemporânea. São Paulo: Estação das Letras, 2006.

SKOL. Reposter. Disponível em: <http://www.skol.com.br/reposter/\#home> Acesso em: 18 abr. 2017. 
TAVARES, Fred. Gestão da marca: estratégica e marketing. Rio de Janeiro: E-papers Serviços Editoriais Ltda, 2003.

TAVARES, Mauro Calixta. A força da marca: como construir e manter marcas fortes. São Paulo: Harbra, 1998.

VIDAL, Marciano. Feminismo e ética: Como “feminizar" a moral. São Paulo: Edições Loyola, 2005.

VIEIRA, Stalimir. Marca: o que o coração não sente os olhos não vêem: reflexões sobre marketing e ética. São Paulo: Loyola, 2002.

WAISELFISZ, Julio Jacobo. Mapa da Violência 2015: Homicídio de mulheres no Brasil. Brasília: Flacso Brasil, 2015. Disponível em: <http://www.mapadaviolencia. org.br/pdf2015/MapaViolencia _2015_mulheres.pdf> Acesso em: 19 abr. 2017.

WHEELER, Alina. Design de identidade da marca: guia essencial para toda a equipe de gestão de marcas. 3. ed. Porto Alegre: Bookman, 2012. 